\title{
Intracranial Meningeal Melanocytoma: Review of the Literature
}

\author{
Angelo Lavano, Attilio Della Torre, Giorgio Volpentesta, Giusy Guzzi, Marisa De Rose and Mary Romano \\ Department of Neurosurgery, Medical School, University Magna Graecia of Catanzaro, Italy \\ ${ }^{*}$ Corresponding author: Angelo Lavano, Professor, Department of Neurosurgery, Medical School, University Magna Graecia of Catanzaro, Italy, Tel: 3909613647385;
} E-mail: lavano@unicz.it

Received Date: April 29, 2015; Revised Date: July 27, 2015; Published Date: July 31, 2015

Copyright: (C) 2015 Lavano A. This is an open-access article distributed under the terms of the Creative Commons Attribution License, which permits unrestricted use, distribution, and reproduction in any medium, provided the original author and source are credited

\section{Introduction}

Primary pigmented tumors of the cerebrospinal meninges are rare and uncommon group of melanin-containing neoplasms. They include pigmented meningioma, malignant melanoma, meningeal melanocytoma, melanotic schwannoma and melanoblastosis. These tumors are different in biological behavior, treatment and prognosis. Valenti was the first to describe pigmented cells normally found in the leptomeninges [1]. Limas and Tio, with their electron microscopic studies, demonstrated that the cell of origin of the so-called pigmented meningiomas is the melanocyte and not the meningothelial cell [2]. So they were the first to speak about the "meningeal melanocytoma".

The meningeal melanocytoma is often described as a wellencapsulated, nodular, dark brown or black lesion that is firmly attached to the underlying leptomeninges [3]. Histologically they may resemble meningiomas but ultrastructurally they are similar to melanotic tumors of the dermis and uveal tract, thus they are not usually related to abnormalities of cutaneous pigmentation [4]. The differential diagnosis is often so confusing, owing to their similar appearance in CT and MR studies, that is necessary additional diagnostic confirmation with electron microscopy and immunohistochemical analysis. They occur most frequently in the posterior fossa and along the spinal cord, producing neurologic deficits by mass effect rather than by infiltration of adjacent nerve structures, and usually show a benign biological behavior.

\section{Review of the Literature}

In 1988 Jellinger et al. [5] reported a case of a 27 year-old woman with a primary localized, partly encapsulated melanotic tumor broadly attached to the occipital dura and tentorium. After developing transient left-sided hemianopia with papilledema headache, a cranial CT demonstrated a lobulated mass of $6 \mathrm{~cm}$ in diameter with strong contrast enhancement in the right occipital region so the tumor was removed surgically without postoperative irradiation. A CT performed 44 months after surgery demonstrated a solid mass of $4 \mathrm{~cm}$ in diameter in the right posterior fossa and it was necessary remove the tumor a second time. Histology of the first biopsy showed a densely packed oval or elongated cells tumor arranged in bundles and fascicles, with no syncytial pattern, no mitotic figures psammoma bodies or mineral deposits. Immunoperoxidase stains for GFAP, cytokeratin, vimentin, factor VII, NSE were negative, while S-100 protein showed positive staining of tumor cells. Electron microscopy demonstrated a varying number of tumor cells contained mature melanosomes and premelanosomes in various stages of melaninization. The results of the histological investigations on the second biopsy revealed a similar pattern with a considerable increase of cellularity and melanin pigment.
In 1995 Maiuri et al. [6] reported a case of intracranial meningeal melanocytoma of the left sphenoid wing in a 69 year-old man with a history of headache, dizziness, severe right-sided hemiparesis and mixed aphasia. A CT study showed a large round hyperdense tumour in the left fronto-temporal region with marked and homogeneous contrast enhancement and slight perilesional edema. The tumor was removed surgically, on the basis of the surgical aspect of the tumor, a meningeal melanoma was suspected. Histologically the tumor was highly cellular, consisting of closely packed spindle-shaped cells, many melanosomes at varying stages of development and absence of mitotic figures. Immunoperoxidase staining was performed using antibodies against Fibrillary Acidic Protein (GFAP), vimentin, S-100 protein, antimelanoma antibody (HMB-45), Epithelial Membrane Antigen (EMA) and Neuron-Specific Enolase (NSE). Immunohistochemical studies showed negative staining of the neoplastic cells with GFAP, NSE and EMA. Stains for S-100 protein, vimentin and HMB-45 were strongly positive on the majority of cells. The histologic, electron microscopy and immunohistologic studies proved that the neoplasm was a meningeal melanocytoma.

In 2000 Painter et al. [7] described the case of a 35-year-old man with a history of remote closed head injury who presented with new neurologic deficits. A non-contrast CT study showed hyperdensity involving both temporal lobes, frontal lobes, basal meninges and cerebellum. A subsequent contrast-enhanced MR scan of the brain showed enhancement in the basal cisterns extending into the upper cervical spine and throughout the spinal canal. An elective right pterional craniotomy was performed, including biopsy and partial debulking. Light microscopic examination showed the typical appearance of a pigmented lesion. Immunohistochemical stains were positive for S-100 protein, HMB-45 and vimentin, suggesting a pigmented neoplasm of melanocytic origin.

In 2003 Rahimi-Movaghar, et al. [8] reported a rare case of parietal convexity meningeal melanocytoma associated with oculodermal melanocytosis (Nevus of Ota) in a 17-year-old man presented with headache, blindness, progressive lethargy, periods of confusion and disorientation. A CT scan of the brain with IV contrast showed a nonhomogeneously enhancing lesion located in the left parietal region, with shift of ventricles ad midline structures to the right. So the mass was removed surgically. The lesion -a black and encapsulated masswas distinct from the brain but firmly attached to the dura. Light microscopic examination showed sheets of tumor tissue with focal areas of whorled pattern but no pleomorphism, necrosis or abnormal mitosis. Immunohistochemistry revealed positive reactions to HMB-45 and S-100 protein in neoplastic cells and focally positive Epithelial Membrane Antigen (EMA), suggesting the diagnosis of meningeal melanocytoma. 


\section{Discussion}

Primary melanocytic neoplasms are rare lesions arising from normally occurring leptomeningeal melanocytes and not from the meningothelial cell. Embryologic evidence suggests a common origin of melanocytes of the basal layer of the epidermis and the leptomeninges covering the base of the brain and the brain stem. The most commonly involved anatomical regions are: cerebellum, cerebral peduncles, medulla, interpeduncolar fossa and inferior surfaces of the frontal, temporal and occipital lobes. Cases in cervical and thoracolumbar regions are also described [9]. These neoplasms are generally divided into three main types, including diffuse melanosis, meningeal melanocytoma and primary malignant melanoma. These tumors usually behave as a benign, single, often encapsulated, nodular brownish lesion, with the tendency to compress the adjacent tissues rather than to infiltrate nerve structures [3]. A meningioma may mimic this gross appearance if large amounts of hemosiderin are present within the lesion from previous episodes of hemorrhage $[7,10]$. A variety of neurological symptoms may be seen with meningeal melanocytoma like recurrent headache, hydrocephalus, seizures, chronic basal meningitis, multiple cranial nerve palsies, psychiatric disturbances, intracranial hemorrhage of the meninges. The preoperative diagnosis is made by neuroradiologic studies with CT, MRI and angiography. CT scan are characterized by iso/hyperdensity lesions with variable contrast enhancement. The MRI appearance is influenced by the content of melanin which causes shortening of $\mathrm{T} 1$ and T2 relaxation times. Generally these tumors have a high signal on T1-weighted studies and a diminished signal on T2-weighted images, with enhancement after contrast administration [11-13]. The angiography shows scarce or no vascular stain. The ultrastructural and immunohistochemical characteristics of these lesions are unique.

\begin{tabular}{|l|l|l|l|l|}
\hline & Meningeal Melanocytoma & Melanocytic Schwannoma & Melanocytic Meningioma & Melanoma \\
\hline HMB-45 & + & +- & - & ++ \\
\hline S-100 PROTEIN & + & ++ & - & + \\
\hline VIMENTIN & + & + & + & - \\
\hline EMA & - & - & + & - \\
\hline GFAP & - & +- & - & - \\
\hline Leu7 & - & + & - & - \\
\hline
\end{tabular}

Table 1: Immunohistochemical features of pigmented tumors of the meninges.

\begin{tabular}{|c|c|c|c|c|c|c|c|}
\hline Authors & Age/Sex & Location & Symptoms/signs & $\begin{array}{l}\text { Radiologic } \\
\text { diagnosis }\end{array}$ & Treatment & Pathologic diagnosis & Follow-up \\
\hline $\begin{array}{l}\text { Jellinger et al. } \\
{[5]}\end{array}$ & $27 \mathrm{~F}$ & $\begin{array}{l}\text { Right occipital } \\
\text { region }\end{array}$ & $\begin{array}{l}\text { Headache, left-sided } \\
\text { hemianopia, } \\
\text { papilledema }\end{array}$ & CT & $\begin{array}{l}\text { Complete } \\
\text { removal }\end{array}$ & Light and electron microscopy & $\begin{array}{l}\text { Recurrence at } \\
44 \text { months, } \\
\text { reoperation }\end{array}$ \\
\hline Maiuri et al. [6] & $69 \mathrm{M}$ & $\begin{array}{l}\text { Left sphenoid } \\
\text { wing }\end{array}$ & $\begin{array}{lr}\text { Headache, } & \text { dizziness, } \\
\text { right-sided } & \text { motor } \\
\text { weakness, } & \text { speech } \\
\text { disturbances } & \end{array}$ & CT, angiography & $\begin{array}{l}\text { Partial removal } \\
\text { and irradiation }\end{array}$ & $\begin{array}{l}\text { Light and electron microscopy, } \\
\text { immunohistochemistry }\end{array}$ & No recurrence \\
\hline $\begin{array}{l}\text { Painter et al. } \\
{[7]}\end{array}$ & $35 \mathrm{M}$ & $\begin{array}{l}\text { Basal cisterns } \\
\text { extending into } \\
\text { the upper } \\
\text { cervical spine }\end{array}$ & $\begin{array}{l}\text { Recurrent headache, } \\
\text { cortical blindness }\end{array}$ & $\mathrm{CT}, \mathrm{MRI}$ & Partial removal & $\begin{array}{l}\text { Light microscopy, } \\
\text { immunohistochemistry }\end{array}$ & No recurrence \\
\hline $\begin{array}{l}\text { Rahimi- } \\
\text { Movaghar [9] }\end{array}$ & $17 \mathrm{M}$ & $\begin{array}{l}\text { Left parietal } \\
\text { convexity }\end{array}$ & Headache, blindness & CT & $\begin{array}{l}\text { Complete } \\
\text { resection }\end{array}$ & $\begin{array}{l}\text { Light microscopy, } \\
\text { immunohistochemistry }\end{array}$ & No recurrence \\
\hline
\end{tabular}

Table 2: Data on the reported cases of meningeal melanocytoma.

Histologically, the tumor is composed of oval or elongated cells, may be organized in shape from spindle or fusiform to polygonal; the nuclei are usually large and prominent nucleoli are often described. Necrosis and hemorrhage are generally absent, though O'Brien et al. reported minimal necrosis, and the mitotic figures are also described as few, scanty, occasional or single [14-16]. The tumor cells may present different degrees of melanization. However the pigment stains negatively for iron. These signs and the absence of cytological signs of malignancy contradict the diagnosis of melanoma while the lack of desmosomes and interdigitating cytoplasmatic processes contradict the diagnosis of meningioma. Immunohistochemical analysis is important to differentiate meningeal melanocytoma from other similar lesions. Meningeal melanocytoma is positive to anti-melanoma antibody (HMB-45), S-100 protein, vimentin antibodies (rarely present in malignant melanoma) and by a negative reaction to Epithelial Membrane Antigen (EMA). Melanocytic meningioma is characterized by a positive reaction to EMA and vimentin, and by a negative reaction to $\mathrm{HMB}-45$ and S-100 protein. A positive reaction to HMB-45 and S-100 protein in the absence of a reaction to EMA provides a reliable diagnostic criterion for the diagnosis of a pigmented lesion, excluding meningioma $[10,17,18]$ (Table 1). The best therapeutic treatment is a complete surgical removal and, if it is 
Citation: Lavano A, Torre AD, Volpentesta G, Guzzi G, Rose MD, et al. (2015) Intracranial Meningeal Melanocytoma: Review of the Literature. Pigmentary Disorders 2: 200. doi:10.4172/2376-0427.1000200

Page 3 of 3

not possible, an incomplete tumor resection combined with a postoperative radiotherapy or stereotactic radiosurgery. However the effectiveness of radiation therapy is not completely clear for this type of lesions. Rades, et al. showed that complete resection was superior to incomplete resection with statistical significance at 1-, 2-, 3-, and 4year follow-up intervals $(\mathrm{p}<0.05)$. incomplete resection with radiotherapy was superior to the incomplete resection alone at 2-year follow-up ( $\mathrm{p}<0.05)$. The survival rates related to different therapeutic approaches were not statistically significant $(p>0.47)$ [19]. Gamma knife radiosurgery has shown to reduce the tumor size and improve clinical outcome. Intrathecal methotrexate or interleukins too have been tried in few cases. Currently, Gross Total Resection (GTR) with adjuvant RT provides the best local control and survival [20] (Table 2).

\section{Conclusion}

Meningeal melanocytomas are benign tumors, but they may present with aggressive behaviors. Complete surgical resection can be curative for most cases. Radiation therapy is important to prevent relapse of the tumor when complete surgical resection is not possible. However the management of melanocytoma has no definite guidelines. The prognosis of meningeal melanocytoma is better than their malignant counterparts [21]. Local recurrences, in spite of the apparently complete surgical removal, suggest that these neoplasm have the possibility of malignant change. For this reason patients should be followed closely to prevent recurrences or the rare event of malignant transition.

\section{References}

1. Clarke DB, Leblanc R, Bertrand G, Quartey GR, Snipes GJ (1998) Meningeal melanocytoma. Report of a case and a historical comparison. J Neurosurg 88: 116-121.

2. Limas C, Tio FO (1972) Meningeal melanocytoma ("melanotic meningioma"): its melanocytic origin as revealed by electron microscopy. Cancer 30: 1286-1294.

3. Russell DS, Rubinstein LJ (1977) Pathology of tumors of the nervous system. (4thedtn). Williams \& Wilkins, Baltimore. 79-80.

4. Mess TH (1986) Tumors of the nervous system. An ultrastructural atlas. Springer, London, UK pp 85-91.

5. Jellinger K, Bock F, Brenner H (1988) Meningeal Melanocytoma Report of a case and review of the literature. Acta Neurochir 94: 78-87.

6. Maiuri F, Iaconetta G, benvenuti D, Lamaida E, De Caro ML (1995) Intracranial meningeal melanocytoma: case report. Surg Neurol 44: 556-561.
7. Painter TJ, Chaljub G, Sethi R, Singh H, Gelman B (2000) Intracranial and intraspinal meningeal melanocytosis. AJNR Am J Neuroradiol 21: 1349-1353.

8. Ruelle A, Tunesi G, Andrioli G (1996) Spinal meningeal melanocytoma: case report and analysis of diagnostic criteria. Neurosurg Rev 19: 39-42.

9. Rahimi-Movaghar V, Karimi M (2003) Meningeal melanocytoma of the brain and oculodermal melanocytosis (Nevus of Ota): case report and literature review. Surg Neurol 59: 200-210.

10. Kepes JJ (1982) Meningiomas. Biology, pathology and differential diagnosis. Masson Publ Inc, New York, USA.

11. Demirci A, Kawamura Y, Sze G, Duncan C (1995) MR of parenchymal neurocutaneous melanosis. AJNR Am J Neuroradiol 16: 603-606.

12. Faillace W, Okawara SH, McDonald JV (1984) Neurocutaneous melanosis with extensive intracerebral and spinal cord involvement. J Neurosurg 61: 782-785.

13. Uematsu Y, Yukawa S, Yokote H, Itakura T, Hayashi S, et al. (1992) Meningeal melanocytoma: magnetic resonance imaging characteristics and pathological features: case report. J Neurosurg 76: 705-709.

14. O’Brien TF, Moran M, Miller JH, Hensley SD (1995) Meningeal melanocytoma. An uncommon diagnostic pitfall in surgical neuropathology. Arch Pathol Lab Med 119: 542-546.

15. Tatagiba M, Boker DK, Brandis A, Samii M, Ostertag H, et al. (1992) Meningeal melanocytoma of the $\mathrm{C} 8$ nerve root: case report. Neurosurgery 31: 958-961.

16. Winston KR, Sotrel A, Schnitt SJ (1987) Meningeal melanocytoma. Case report and review of the clinical and histological features. J Neurosurg 66: 50-57.

17. Lach B, Russell N, Benoit B, Atack D (1988) Cellular blue nevus ("melanocytoma") of the spinal meninges: electron microscopic and immunohistochemical features. Neurosurgery 22: 773-780.

18. Litofsky NS, Zee CS, Breeze RE, Chandrasoma PT (1992) Meningeal melanocytoma: diagnostic criteria for a rare lesion. Neurosurgery 31: 945-947.

19. Rades D, Heidenreich F, Tatagiba M, Brandis A, Karstens JH (2001) Therapeutic options for meningeal melanocytoma. Case report. J Neurosurg 95: 225-231.

20. Liubinas SV, Maartens N, Drummond KJ (2010) Primary melanocytic neoplasms of the central nervous system. J Clin Neurosci 17: 1227-1232.

21. Steinberg JM, Gillespie JJ, MacKay B, Benjamin RS, Leavens ME (1978) Meningeal melanocytoma with invasion of the thoracic spinal cord. Case report. J Neurosurg 48: 818-824. 